\title{
TRECHOBLEMUS IN NORTH AMERICA, WITH \\ A KEY TO NORTH AMERICAN GENERA \\ OF TRECHINAE (COLEOPTERA: CARABIDAE)
}

\author{
By Thomas C. Barr, Jr. \\ The University of Kentucky, Lexington
}

Trechoblemus Ganglbauer is a genus of trechine beetles (Trechinae: Trechini: Trechina) previously known only from Europe and Asia. It formed the type genus of Jeannel's "Série phylétique de Trechoblemus", and is generally regarded as closely related to cavernicolous trechines in Japan, the Carpathians and Transylvanian Alps of eastern Europe, and eastern United States (Barr, 1969; Jeannel, 1928, 1962; Uéno and Yoshida, 1966). The large cave beetle genus Pseudanophthalmus Jeannel, with approximately 175 species in caves of ten eastern States, the monobasic genus Neaphaenops Jeannel, from Kentucky caves, and the dibasic genus Nelsonites Valentine, from Tennessee and Kentucky, are part of the Trechoblemus complex.

The apparent restriction of Trechoblemus to Eurasia led previous investigators to conclude that, with respect to the richly diverse trechine fauna in caves of eastern United States, "there are no immediate, ancestral genera now present in North America" (Barr, 1969, p. 83). Although there is at least one edaphobitic (obligate in soil) species of American Pseudanophthalmus known ( $P$. sylvaticus Barr, 1967), in the mountains of West Virginia, it has already lost eyes, wings, and pigment, and merely indicates that many of the "regressive" evolutionary changes in ancestral Pseudanophthalmus may have taken place in the soil or deep humus before the beetles became restricted to caves. Most of the species of Pseudanophthalmus from eastern Europe (Barr, 1964) are also eyeless edaphobites.

In March, I97I, I received a series of 5 trechines for determination from Dr. Richard L. Westcott, State Department of Agriculture, Salem, Oregon. These specimens were all taken in black light traps in the Willamette valley between Salem and Portland, northwest Oregon, and proved to belong to an undescribed species of Trechoblemus, the first species of the genus to be discovered in North America.

There are at least two other zoogeographic links between the forests of the Pacific Northwest and those of the southern Appalachians, when one looks at the carabid faunas as a whole. The 


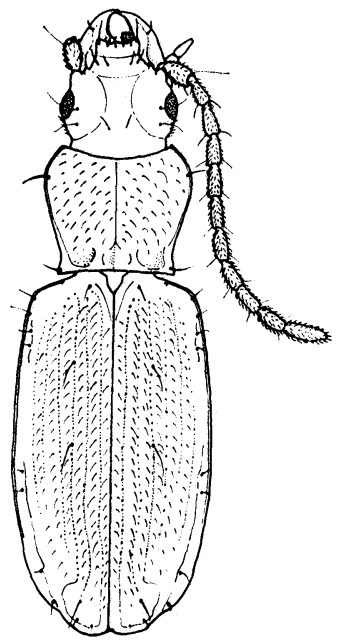

Figure 1. Trechoblemus avestcotti, new species. Hillsboro, Washington County, Oregon. Holotype male, length $4.6 \mathrm{~mm}$.

small, burrowing cychrines of the genus Maronetus are endemic to the southern Applachians, but are more closely similar to cychrine genera of the Pacific Northwest than they are to other eastern cychrines (Barr, in press). The subgenus Amerizus of the large genus Bembidion includes only two species, $B$. $(A$.$) oblongulum$ Herbst in the Northwest and $B .(A$.) wingatei Bland in the southern Appalachians (Lindroth, I96I). Both of these groups, like Trechoblemus-Pseudanophthalmus, are more or less humicolous or subterranean. Within the large, widely-distributed genus Pterostichus, the species of the California-Northwest subgenus Hypherpes share a close similarity in appearance and habits with those of the Appalachian subgenus Haplocoelus (cf. Barr, 1969, footnote p. 80). Until both subgenera have been carefully studied, however, it is not possible to state whether these similarities are the result of phylogenetic relationship or convergence.

The relatively few close ties between the Pacific Northwest and Appalachian forest carabid faunas do suggest, however, that the two faunas have been isolated from each other for a long time. The beginning of the period of isolation presumably began in the Miocene with the establishment of the Great Plains. If the Trechoblemus-like ancestors of Pseudanophthalmus arrived in North America via a Bering land bridge, their arrival was probably pre-Miocene. Certainly the considerable diversity (approximately 20 species groups 


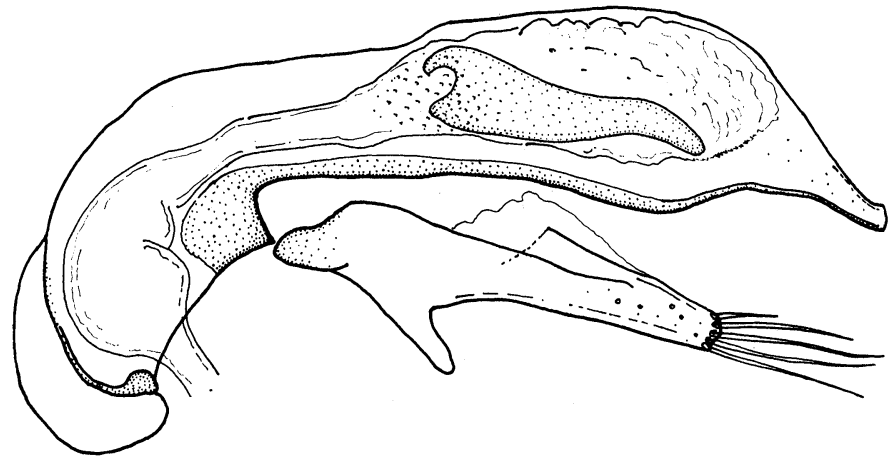

Figure 2. Trechoblemus westcotti, new species. Hillsboro, Washington County, Oregon. Aedeagus of holotype male, length $0.92 \mathrm{~mm}$. , left lateral view.

at present) and fairly wide distribution that Pseudanophthalmus ancestors had achieved prior to colonization of caves during the Pleistocene must have required a rather long period of time, a supposition which at least accords with postulating an ancestral stock from the Northwest.

\section{Trechoblemus westcotti, new species}

Figures I, 2

Length 4.3-4.8 mm., mean 4.5 mm. Pale castaneotestaceous, head a little darker, usually with a faint, nebulous, darker fascia on apical half of elytra; integument pubescent, shining, microsculpture finely isodiametric on head and very finely transverse, iridescent, on pronotum and elytra. Functional wings present. Head rounded; labrum distinctly but not very deeply bisinuate; surface with scattered, rather long pubescence, especially on sides and beneath; eyes feebly convex, about $0.3 \mathrm{~mm}$. high $\times 0.2 \mathrm{~mm}$. long; mentum fused to submentum, mentum tooth conspicuous and deeply emarginate; I I-I 2 prebasilar setae. Pronotum transverse, about I.3 times wider than long, disc convex, with long, rather dense pubescence; greatest width in apical fourth, widths at apex and base subequal to each other and also to length; sides arcuate in apical half, then convergent, distinctly sinuate in basal fifth; anterior angles prominent; hind angles large, sharp, prominent, a little less than right; antebasal foveae large and deep; base entire; anterior marginal seta placed just behind greatest width, posterior seta just before hind angles. Elytra elongate-oval, r.8 times longer than wide, broadly 
subconvex, distinct humeri present, prehumeral borders slightly oblique to mid-line; disc densely pubescent, microsculpture very fine, nearly obsolete but perceptibly transverse and iridescent; inner three longitudinal striae more or less complete, fourth and fifth striae joining in apical third, sixth stria shorter than seventh, all striae somewhat irregularly punctulate and progressively shallower toward margin; intervals subconvex; apical recurrent groove rather short and subparallel to suture, joining third stria in a short crosier in advance of anterior apical puncture; humeral group of umbilicate punctures closely spaced against marginal gutter; two discal punctures on fourth interval, anteriormost behind level of fourth umbilicate; apical triangle normal for genus. Antenna a little more than half total body length, with all segments more or less pubescent. Aedeagus of holotype $0.92 \mathrm{~mm}$. long, gently arcuate, membranous above, with a ventral preapical boss, apex briefly and narrowly produced, finely reflexed at the very tip; copulatory piece single, concave toward right wall of internal sac, apically attenuate and rounded, about one third as long as aedeagus; parameres with five apical setae.

Holotype male, Hillsboro, Washington County, Oregon, July 27, 1965, taken in a black light trap by Kenneth Goeden; deposited in collection of the State Department of Agriculture, Salem, Oregon. Four female paratypes, taken in black light traps in northwestern Oregon, as follows: Marion County: Salem, July 15, 1969; Io miles northeast of Salem, August 9, 1969: Pudding River, 3 miles east of Woodburn, August 2, I968. Washington County: 5 miles northeast of Newberg, August I, I966.

Measurements of holotype: total length $4.6 \mathrm{~mm}$., head $0.86 \mathrm{~mm}$. long $\times 0.88 \mathrm{~mm}$. wide, pronotum $0.84 \mathrm{~mm}$. long $\times 1.08 \mathrm{~mm}$. wide, pronotum $0.80 \mathrm{~mm}$. wide at apex and $0.82 \mathrm{~mm}$. wide at base, elytra $2.64 \mathrm{~mm}$. long $\times 1.46 \mathrm{~mm}$. wide, antenna $2.54 \mathrm{~mm}$. long, aedeagus $0.92 \mathrm{~mm}$. long.

Discussion: Superficially $T$. westcotti closely resembles $T$. micros Herbst and $T$. postilenatus Bates, European and Japanese species, respectively. The apical recurrent groove, however, is less rounded than in those species, and the aedeagus with its less arcuate form, ventral preapical boss, and briefly produced, truncate, slightly reflexed apex is distinctive. The general form of the aedeagus recalls that of Trechoblemus microphthalmus Uéno, from Takarajima, one of the Tokara Islands (Uéno, I955, pp. 404-405, fig. I), but T. microphthalmus is a smaller, brachypterous species with smaller eyes and smaller aedeagus. Among North American species of Trechinae 
the only species with which it might readily be confused is Lasiotrechus discus (F.), which also has eyes, wings, pubescent integument, and similar coloration. L. discus, however, has large, convex eyes, a strongly cordiform pronotum, an apical recurrent groove which is oblique to the suture, and most of the longitudinal striae vanish before reaching the apex.

Key to Nearctic Genera of Trechinae

I. Eyes pubescent; form elongate-subparallel, depressed; head with deep, sulcate frontal grooves extended backward onto sides of head; West Indies ..... Perileptus Schaum

Eyes glabrous or absent

2(I). Form elongate-subparallel, depressed; head with deep, sulcate frontal grooves extended backward onto sides of head; elytra with second longitudinal stria beginning at level of anterior discal puncture, third stria obsolete behind anterior discal; aedeagus with basal bulb opening between two lobes; color black or piceous; in North America known only from Panama to southern Mexico

Cnides Motschulsky

Elytral striation not as described; frontal grooves not sulcate; basal bulb of aedeagus closed except for normal basal orifice

3(2). Mandibles with a premolar tooth between retinaculum and and mola; color black, form Trechus-like, elytral discal punctures not on fifth stria; in North America, known only from Panama .............. Trechisibus Motschulsky

Mandibles without a disinct premolar tooth ............. 4

4(3). Elytra with anterior discal puncture on or near fifth stria OR if anterior discal puncture is absent, specimen microphthalmous, depigmented, from cave in Mexico ...... 5

Elytra with anterior discal puncture on or near third (rarely fourth) stria $\mathrm{OR}$ if anterior discal puncture absent, then specimen is not from cave in Mexico ... 6

5(4). Color rufotestaceous; eyes reduced to minute, pale areolae: form elongate, frontal grooves short, neck very narrow; inhabitants of caves in Mexico

Mexaphaenops Bolívar

Color black or piceous to pale piceous; eyes normal, or if reduced to pale areolae (Querétaro, Mexico), then frontal grooves normal, neck not very narrow; moun- 
tains or caves, Mexico to Costa Rica and possibly Panama .................................... Paratrechus Jeannel

6(4). Eyes normal ........................................................... 7

Eyes absent or rudimentary; inhabitants of caves or of deep soil in mountainous regions

7(6). Color black or piceous; glabrous, polished integument; range: most of Canada, United States including Alaska (absent from southern Great Plains and Altantic and Gulf coastal plains), central highlands of Mexico

Trechus Clairville

Color more or less testaceous, integument densely pubescent

8(7). Darker, with prominent, blue-black fascia across elytra; pronotum cordiform; eyes very convex; longitudinal striae disappearing before apex; apical recurrent groove oblique to suture; eastern Canada and New England Lasiotrechus Ganglbauer

Paler, elytral fascia nebulous or absent; pronotum transverse-subquadrate; eyes feebly convex; at least inner three longitudinal striae complete; apical recurrent groove subparallel to suture, conspicuously joining third stria; northwest Oregon .... Trechoblemus Ganglbauer

9(6). Mentum separated from submentum by distinct suture; submentum with row of four long (prebasilar) setae; basolateral margins of pronotum with two or three prominent teeth; known only from caves in vicinity of St. Louis and Ste. Genevieve, Missouri

Xenotrechus Barr and Krekeler

Mentum fused to submentum; submentum with transverse row of six to twelve setae; basolateral margins of pronotum without teeth; range: east of Mississippi River

IO

Io(9). Head with one pair of supraorbital setae; form elongate, subconvex, elytron without anterior apical puncture $(++0)$; last segment of maxillary palp shorter than penultimate segment; length 6-7 $\mathrm{mm}$.; western Pennyroyal plateau of Kentucky ......... Neaphaenops Jeannel

Head with two pairs of supraorbital setae (rarely more than two); last segment of maxillary palp subequal in length to penultimate segment

II (IO). Anterior tibia subglabrous on external face; anterior apical puncture of elytron very small, not setigerous $(++0)$; 
length 6-8 $\mathrm{mm}$., elongate, more or less glabrous, convex; southeastern Kentucky (Estill, Jackson, Rockcastle, Pulaski, Clinton, Wayne, and McCreary counties) and adjacent Tennessee (Fentress County)

Darlingtonea Valentine

Anterior tibia rather densely pubescent on external face; anterior apical puncture setigerous, or if absent (Adair County, Kentucky), then posterior discal puncture also absent $(+++,+\mathrm{o}+, \mathrm{oo}+$, or $+\mathrm{oo})$.......... I2

I2 (II). Antenna as long as body, attaining elytral apexes when laid back; length 5.5-7.0 mm.; head and mandibles very large, all appendages elongate and slender; anterior discal punctures of elytra at level of second umbilicate AND prehumeral borders sharply oblique to mid-line; Cumberland plateau margin from Jackson County, Kentucky, southwestward to Van Buren County, Tennessee

Nelsonites Valentine

13(12). Right mandible with retinaculum 5-tuberculate, anterior two and posterior three teeth separated by a deep emargination; apex of aedeagus more or less umbonate in ventral view, transfer apparatus a single median ventral sclerite; length 4.5-6.0 mm., form robust, elytra usually more or less pruinose; southeastern Kentucky (Jackson, Rockcastle, Pulaski, northern Wayne and McCreary counties) ........... Ameroduvalius Valentine Right mandible with retinaculum usually 2- to 4-tuberculate, without a conspicuous gap separating teeth; apex of aedeagus not as described; transfer apparatus of one or two sclerites, placed edgewise in internal sac Pseudanophthalmus Jeannel

Pseudanophthalmus appears last because it is the largest and most variable genus of nearctic trechines, and the key has been constructed to split off the other genera one at a time. The last couplet is the most inconvenient for rapid sorting because it requires removing a mandible and/or an aedeagus. As a practical matter this can usually be avoided because most species of Pseudanophthalmus do not occur within the range of Ameroduvalius, but most of those that do are either under $4 \mathrm{~mm}$. in length or have obliquely sloping prehumeral borders. For Pseudanophthalmus species in the same size range as Ameroduvalius (4-5 mm., Wayne and McCreary counties, Kentucky), males can be readily distinguished by the 
absence of the diagnostic, wing-like expansions of the aedeagus so characteristic of $A$. jeanneli (Valentine, 1952). The + 's and -'s in couplets IO and II are a shorthand for presence $(+)$ or absence (-) of the anterior discal, posterior discal, and anterior apical punctures, respectively, of the elytra.

\section{A Prospectus of the North American Trechinae}

The following classification is within the framework proposed by Uéno (in Uéno and Yoshida, 1966, footnote, p. 77). The starred (*) subtribes are not represented in North America. Other than adding newly described genera, I have diverged from the "series" classification of Jeannel (1928) only in putting Lasiotrechus into the Trechoblemus series. The "Darlingtonea series" is a new category for two genera described by Valentine (1952) and seen by Jeannel only a year before his death. He felt that Ameroduvalius was not closely related to any trechine genus known to him and had the impression that Darlingtonea was very close to Pseudanophthalmus (Jeannel, in litt.). Quite probably Jeannel relied on the aedeagal figures drawn by Valentine (op. cit.), and was thus misled about the nature of the transfer apparatus in Darlingtonea; instead of consisting of two spatulate sclerites, the Darlingtonea copulatory pieces are dorsal/ventral and isotopic, like the two halves of a box.

Tribe Trechodini

Subtribe Cnidina

Cnides Motschulsky - 3 spp.; southern Mexico to Panama

Subtribe Trechodina*

Subtrible Plocamotrechina*

Tribe Perileptini

Perileptus Schaum - 4 spp.; West Indies

Tribe Trechini

Subtribe Aepina*

Subtribe Aemaloderina

Trechisibus Motschulsky - I sp.; Panama (many spp. in South America)

Subtribe Trechina

I) Trechoblemus series

Trechoblemus Ganglbauer - I N.A. sp.; Oregon

Lasiotrechus Ganglbauer - I N.A. sp.; eastern Canada and New England 
Pseudanophthalmus Jeannel - approximately I 75 spp.; Alabama, Georgia, Illinois, Indiana, Kentucky, Ohio, Pennsylvania, Tennessee, Virginia, West Virginia

Nelsonites Valentine - 2 spp.; Kentucky and Tennessee

Neaphaenops Jeannel — I sp.; Kentucky

2) Aphaenops series

Xenotrechus Barr and Krekeler - 2 spp.; Missouri

3) Darlingtonea series

Darlingtonea Valentine - I sp.; Kentucky and Tennessee Ameroduvalius Valentine -3 spp.; Kentucky

4) Paratrechus series

Paratrechus Jeannel - approximately $20 \mathrm{spp}$; Mexico to Costa Rica

Mexaphoenops Bolívar - 5 spp.; northeastern Mexico

5) Trechus series

Trechus Clairville - approximately 40 spp.; mountainous and northern regions, also central highlands of Mexico

Barr, Thomas C., Jr.

\section{Literature Cited}

1964. The status and affinities of Duvaliopsis Jeannel (Coleoptera: Carabidae). Psyche, vol. 71, pp. 57-64.

1967. A new Pseudanophthalmus from an epigean environment in West Virginia (Coleoptera: Carabidae). Psyche, 74: 166-172.

1969. Evolution of the Carabidae (Coleoptera) in the southern Appalachians. In: Holt, P. C., ed. The distributional history of the biota of the southern Appalachians. Virginia Polytechnic Inst., Res. Mon. 1, pp. 67-92.

1971. In press. Studies on the cychrine beetles of eastern North America (Coleoptera: Carabidae). Bull. American Mus. Nat. Hist.

Jeannel, René

1928. Monographie des Trechinae. Morphologie comparée et distribution géographique d'un groupe de Coléoptères ( $3^{e}$ livraison). L'Abeille, $35:$ 1-808.

1962. Les Trechini de l'Extrème-Orient. Rev. francaise d'Entomol., 29: 171-207.

Lindroth, CARL H.

1961. The ground-beetles of Canada and Alaska, part 2. Opusc. Entomol., suppl. $20: 1-200$.

UÉNO, SHUN-ICHI

1955. Marine insects of the Tokara Islands. VII. New species and new subspecies of the subfamily Trechinae (Coleoptera, Harpalidae). Publ. Seto Mar. Biol. Lab., 4: 403-413. and Akira Yoshida 
1966. A presumptive prototype of the Trechoblemus complex (Coleoptera, Trechinae). Bull, Nat. Sci. Mus., Tokyo, 9: 75-83.

VAlentine, J. Manson

1952. New genera of anophthalmid beetles from Cumberland caves (Carabidae, Trechini). Geol. Surv. Alabama, Mus. Pap. 34, 41 pp. 

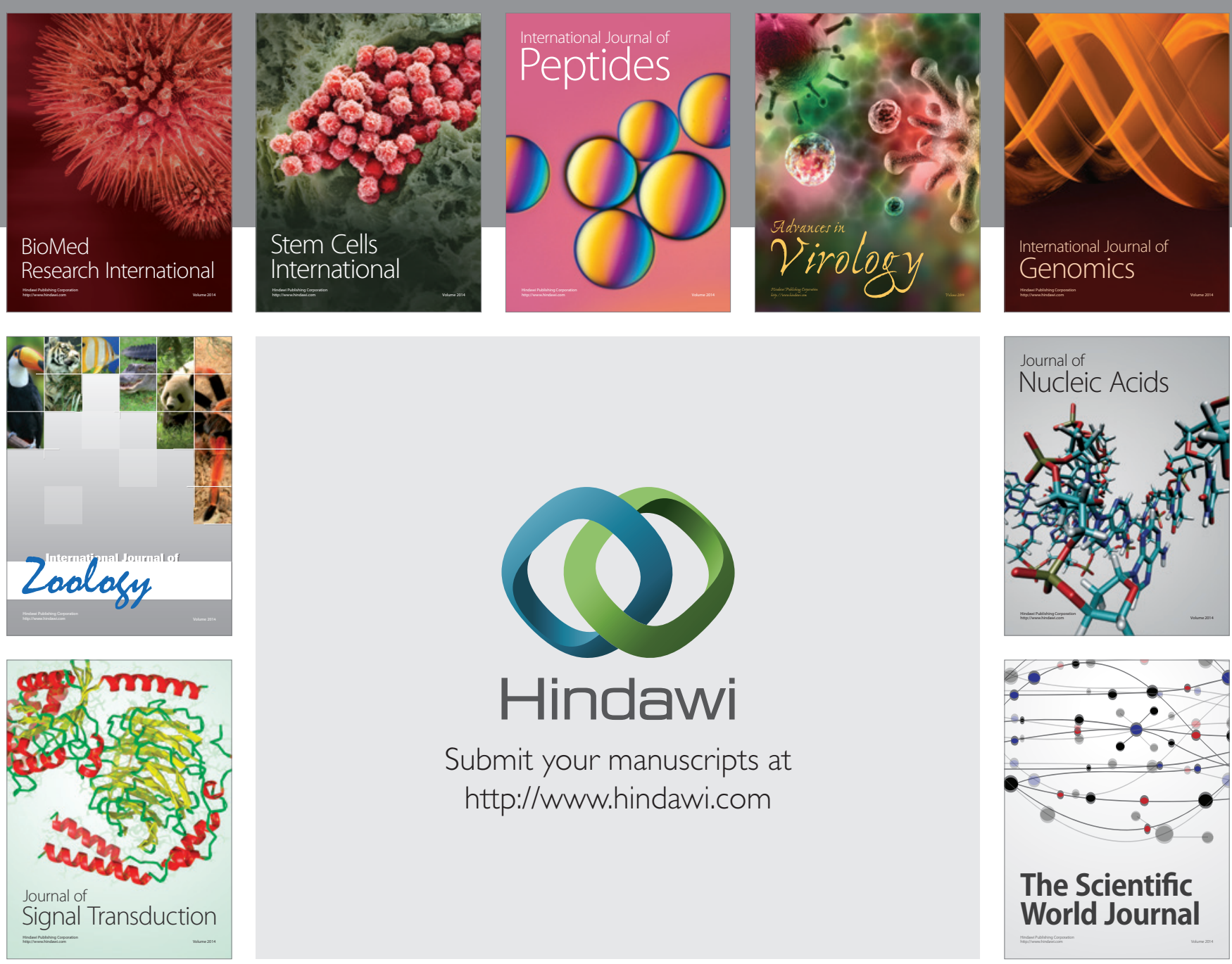

Submit your manuscripts at

http://www.hindawi.com
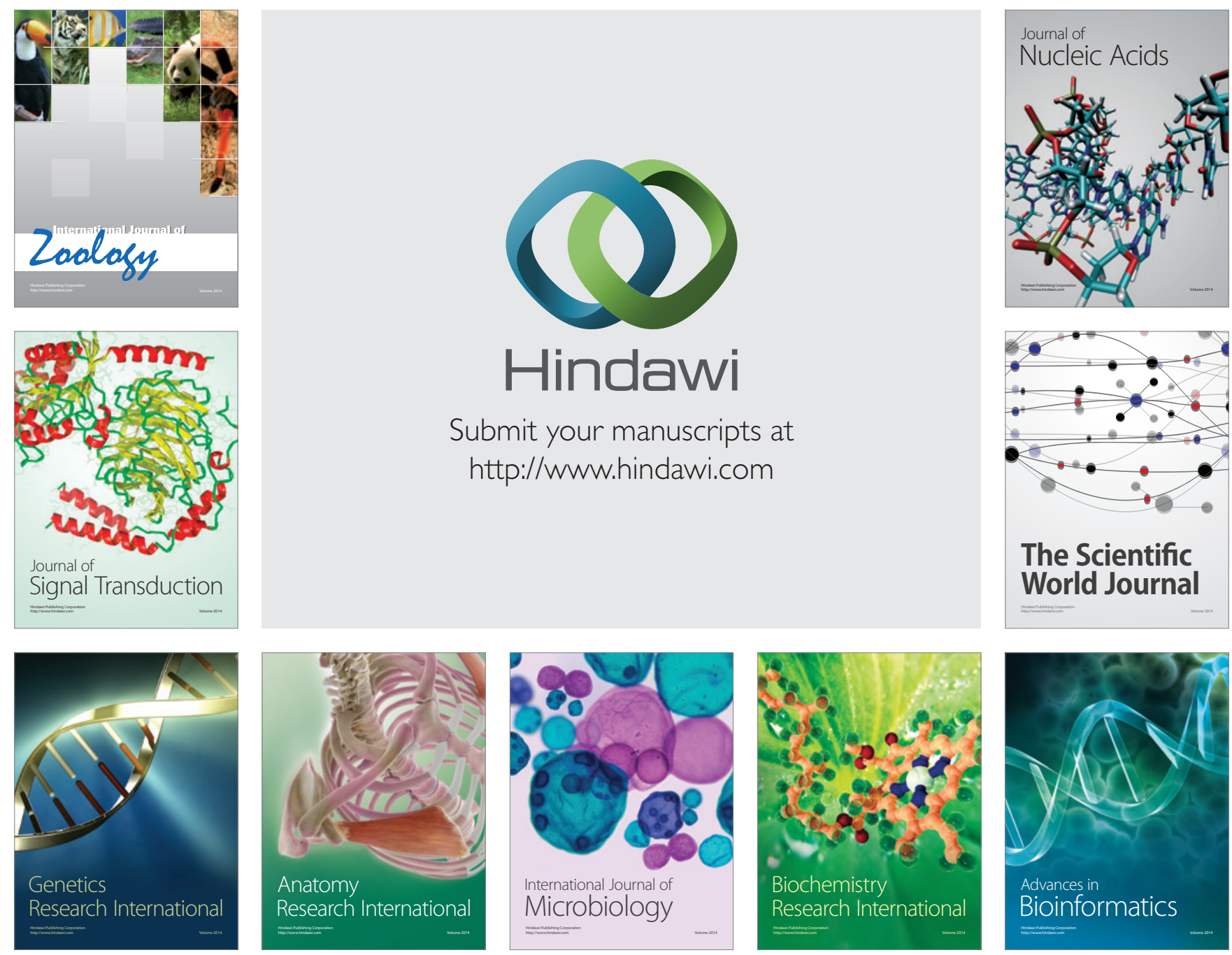

The Scientific World Journal
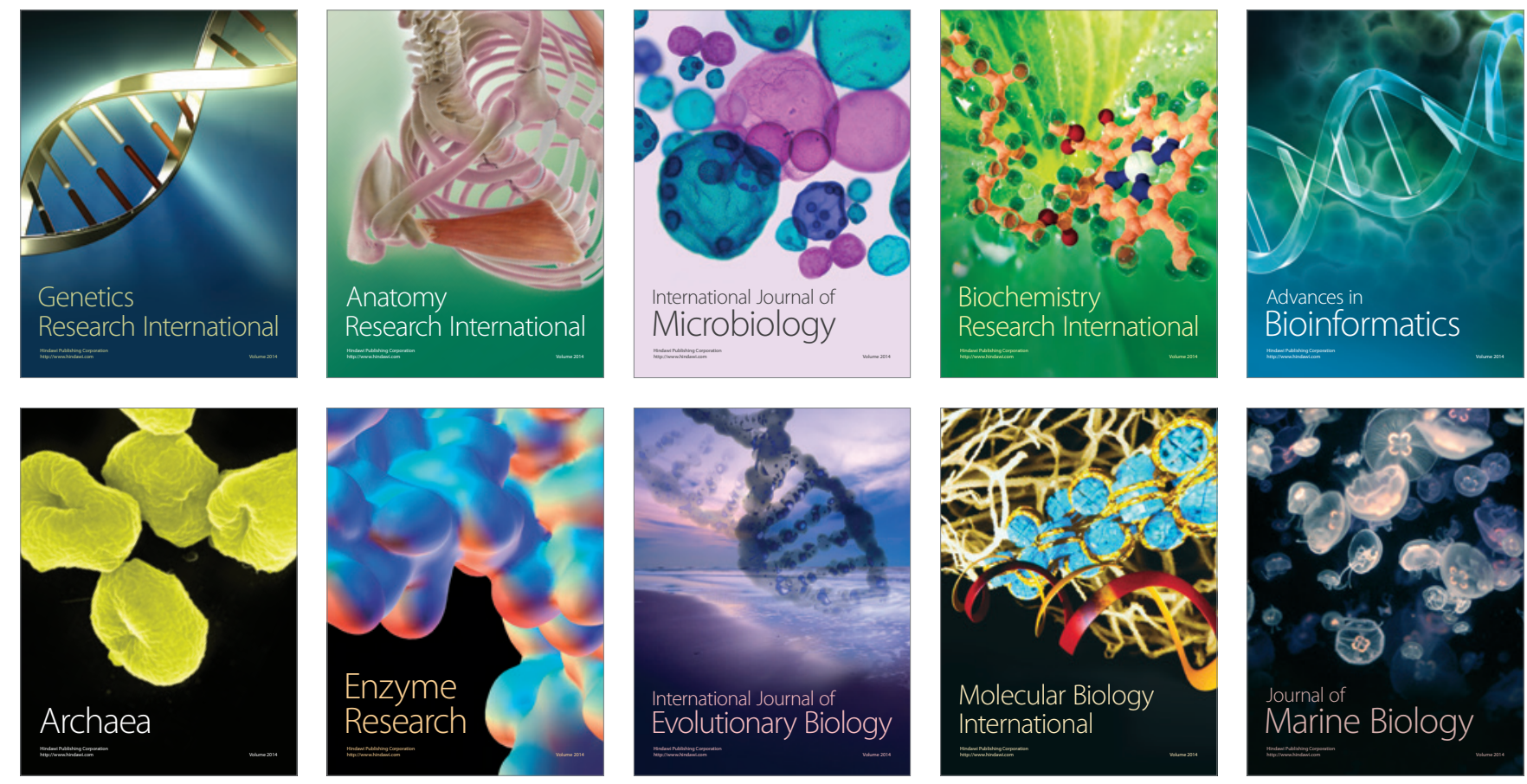